REVISTA DE DERECHO UNED, NÚM. 17, 2015

\title{
LA CÁRCEL: INVENCIÓN RECIENTE. SURGIMIENTO DE LA PENA PRIVATIVA DE LIBERTAD EN ESPAÑA
}

\author{
PRISON: RECENT INVENTION. EMERGENCE OF \\ IMPRISONMENT IN SPAIN
}

José Ginés CARRAsco GuiJARRo

Jurista del Cuerpo Superior de Técnicos de Instituciones Penitenciarias

Resumen: Los siglos XVI, XVII y XVIII, con la caída del Antiguo Régimen, vieron nacer la privación de libertad como pena al amparo de una Monarquía Absoluta que desbancó el modelo señorial de Señorcriado. La pena de privación de libertad y las galeras como su primera encarnación en la España moderna devolvía a esa condición de siervo de la que aparentemente se había desgajado el hombre del quinientos, pero el patrón ya no era el Señor, sino el Rey. De este modo, ante la aparición del hombre libre, cobra sentido la privación de libertad como pena sustantiva, excediendo el encierro de la finalidad de mera custodia que, salvo excepciones, había primado en los siglos anteriores. Existen una serie de factores que influyen en el devenir de la vida penitenciaria: en primer lugar, en el plano político, estamos ante una clara hegemonía militar, con una marcada política de defensa. En segundo lugar, el apogeo legislativo, que pone en marcha nuestra historia Constitucional y de Codificación, no escapando el ámbito penitenciario a esta idea de unificación normativa. En tercer lugar, la aplicación de las ideas desamortizadoras que configurará el campo de la arquitectura penitenciaria en nuestro país. Y por último, la entrada de nuevas corrientes filosóficas, que culminan a finales de siglo con el Krausismo y el positivismo científico. 
El triunfo del encierro se basa en varias razones. En primer lugar, una razón de política criminal ante la aparición de una nueva delincuencia de carácter económico, que aunque de escasa entidad, era muy numerosa, provocada por la miseria y las dificultades de la época. Una segunda razón penológica que se centra en el desprestigio de la pena de muerte y, por último, una razón político- económica, alumbrada por Foucault, consistente en la condena a la ociosidad de la incipiente sociedad burguesa, lo cual acuña el carácter utilitarista del nuevo modelo de encierro.

Palabras clave: Pena, privación de libertad, encierro, cárcel, presidio, reclusión, corrección, penitenciarismo, reglamentos.

Abstract: The sixteenth, seventeenth and eighteenth centuries, with the fall of the ancien regime gave birth imprisonment as a penalty under an absolute monarchy that ousted the feudal Lord-servant model. The penalty of imprisonment and the galleys as its first incarnation in modern Spain returned to the serfdom of which had apparently broken off the five hundred men, but the pattern was not the Lord, but the King. Thus, at the onset of the free man, makes sense deprivation of liberty as a substantive worth, exceeding the closure of the purpose of mere custody exceptions, he had prevailed in previous centuries. There are a number of factors that influence the evolution of prison life: first, at the political level, we have a clear military hegemony, with a strong defense policy. Second, the legislative swing, which launches our constitutional history and Codification no escaping the prison environment legislation to this idea of unification. Third, the implementation of disentail ideas configure the field of prison architecture in our country. And lastly, the entry of new philosophical currents, culminating at the end of the century with the Krausismo and scientic positivism.

The triumph of closure is based on several reasons. First, a reason for criminal policy at the onset of a new economic crime, although only minor, was very large, caused by poverty and the difficulties of the time. A second penological reason that focuses on the prestige of the death penalty, and finally, an economic-political reason, illuminated by Foucault, consistent in condemning the idleness of the nascent bourgeois society, which coined the utilitarian character new model of confinement.

Keywords: Pena, detention, imprisonment, jail, prison, detention, correction, penitentiary usage, regulations.

Sumario: Introducción. 1. Surgimiento de la pena privativa de libertad en España. 2. El presidio como vertiente penitenciaria. 3. Re- 
clusión en las casas de corrección. 4. La idea de la cárcel-modelo. 5. Producción normativa penitenciara en el siglo XIX. 6. Conclusión Personal. 7. Bibliografía.

\section{INTRODUCCIÓN}

La ejecución de cualquier pena supone, como es obvio, la existencia de un determinado lugar, de un espacio en donde el condenado sufra el castigo impuesto, bien se trate de una plaza pública, de las calles de una ciudad o de la parte más recóndita de una galera.

Mientras ese lugar no sea sino el soporte, el marco donde la sentencia se cumple, su forma característica y condiciones son problemas de importancia secundaria. Así, por ejemplo, cuando la pena de muerte pasó a ejecutarse en el interior de las cárceles, lo único que se alteró con ello fue una nota adjetiva, como es la publicidad, mientras que, por el contrario, el contenido esencial de la pena no sufrió modificación alguna. Sin embargo, cuando pensamos en la pena de privación de libertad, la cárcel, el lugar en donde la sentencia se cumple, ya no es meramente un ámbito, un elemento más o menos accidental y de escasa trascendencia. Es la propia prisión la que se convierte en factor punitivo desde el momento en que la sentencia judicial condena al reo a permanecer en una cárcel durante un período de tiempo.

\section{SURGIMIENTO DE LA PENA PRIVATIVA DE LIBERTAD EN ESPAÑA}

La pena privativa de libertad, como tal pena, nació en un momento relativamente cercano a nosotros. Ni el mundo antiguo ni el medieval hicieron uso de ella. Sin embargo, hay algunas excepciones a esta regla general que merecen ser señaladas, como lo pone de manifiesto la opinión de Manuel de Lardizabal y Uribe, quien en 1782 afirmaba: «Aunque la cárcel no se ha hecho para castigo, sino para custodia y seguridad de los reos, como se ha dicho, sin embargo, suele imponerse por pena en algunos delitos que no son de mucha gravedad» ${ }^{1}$.

Retrotrayéndonos más en el tiempo, encontramos que incluso ya en la Edad Media la privación de libertad tuvo verdadero carácter punitivo «aplicada a los deudores también subsidiariamente en caso

${ }^{1}$ LARDIZABAL Y URIBE, M.: Discurso sobre las penas contraido a las leyes criminales de España para facilitar su reforma. Ed. Porrúa, México, 1982, pág. 211.

(C) UNED. Revista de Derecho UNED, núm. 17, 2015 
de falta de pago de la pena pecuniaria impuesta y asimismo como pena principal» ${ }^{2}$. También hay que hacer mención al procedimiento inquisitorial en el que el encarcelamiento era bastante común y podía durar desde varios meses a toda la vida; sin embargo, como señala KAMEN «esta pena en la mayoría de los casos no suponía la efectiva reclusión en una cárcel, sino que, a discreción del Tribunal, el individuo podía ser confinado en su domicilio, en un convento o en un hospital $»^{3}$. La razón para esa benevolencia era que muy a menudo los tribunales no tenían sitio en sus prisiones. En otro orden de cosas, hay otras dos excepciones a esta regla general que destacan por su importancia, pues, para algunos autores, constituyen el origen de la pena privativa de libertad tal y como la entendemos: son las llamadas prisiones del Estado y la prisión eclesiástica.

En cuanto a las primeras, Garrido Guzmán señala que en ellas «solo podían recluirse los enemigos del poder, real o señorial, que habían incurrido en delitos de traición o a los adversarios políticos detentadores del poder, y cuando adquiere la forma de detención temporal ó perpetua es cuando aparece la privación de libertad como pena propia y autónoma» ${ }^{4}$. En lo relativo a la prisión eclesiástica, el mismo autor nos dice que estaba destinada a sacerdotes y religiosos y que tenía lugar recluyéndoles en un ala de los monasterios a fin de que, por medio de la oración y la penitencia, reconociesen la entidad del mal causado y lograsen su corrección o enmienda. Este ala era denominada ergastulum, nombre procedente del Derecho Romano, y hacía referencia a las cárceles domésticas para esclavos.

Aunque la cárcel no tuvo un carácter punitivo hasta finales del siglo XVII, algunas otras penas suponían de hecho una efectiva privación de libertad, como, por ejemplo, la de galeras (aparecida en el siglo XVI, fue suprimida en 1748, restablecida en 1784 y abolida por fin en 1803) o la de laboreo en minas (que era considerada una variante de la pena de galeras). La pena privativa de libertad adquiere su verdadera condición como tal pena al abolirse la de galeras y ser enviados los que la sufrían a los presidios de África y a los arsenales.

Esta fue la situación dominante en líneas generales hasta finales del siglo XVII. Desde entonces, el encarcelamiento vino a introducirse en el repertorio de penas, con escasa relevancia primero para ir incre-

${ }^{2}$ CUELLO CALON, E.: La moderna penología. Ed. BOSCH, Barcelona, 1958, pág. 356.

${ }^{3}$ KAMEN, H.: La inquisición española. Ed. Crítica, Barcelona, 1979, págs. 200-201.

${ }^{4}$ GARRIDO GUZMÁN, L.: Manual de ciencia penitenciaria. Ed. Edersa, Madrid, 1983, pág. 77 . 
mentándola después. A finales del siglo XVIII y en los primeros años del siglo XIX las modalidades de privación de libertad eran, según Cuello Calón ${ }^{5}$, las siguientes:

a) Trabajos de bombas (que consistía en maniobrar las bombas de achique de los diques del arsenal) y otros penosos en presidios;

b) Trabajos en los presidios de África;

c) Reclusión en los depósitos de rematados y en las cárceles;

d) Reclusión en las casas de corrección.

Con el incremento de la población reclusa, y al ser muy escasos los establecimientos para su custodia, el Gobierno se vio obligado a crear nuevos presidios ya dentro de la península, entre los que destaca la modalidad llamada presidios de obras públicas, en los cuales los presos tenían como cometido construir carreteras, caminos, puertos y demás obras públicas. Con esto, junto a los presidios arsenales, en los que los directores pertenecían a la Armada y los presos trabajaban en bombas, existían también los presidios de la península, dirigidos por militares del ejército de tierra y en los que los reclusos eran empleados en obras de fortificación. Ambos presidios dependían del Ministerio de la Guerra, hasta que en 1834, con la publicación de la Ordenanza de los Presidios del Reino, se convierten en civiles y pasan a depender del Ministerio de Fomento.

De esta manera se fue introduciendo la pena privativa de libertad, que ya va a ser recogida por el primero de nuestros Códigos Penales, el de 1822. En 1834 se dictó la Ordenanza de los Presidios del Reino, que los dividía en depósitos correccionales, presidios peninsulares y presidios de África. En ella se regula la separación en los establecimientos penitenciarios de los menores de dieciocho años y de los condenados a penas infamantes; se establece un régimen de comunidad diurno y nocturno, y, finalmente, se impone la obligación de trabajar. El Código de 1848 marca una nueva etapa, pues aunque mantiene la pena privativa de libertad, le da un contenido nuevo y distinto al que tenía en el Código anterior. El Código de 1870, por su parte, conserva esta misma línea, aunque cambia los nombres de presidio menor y prisión correccional, y todavía encontramos en él penas privativas de libertad acompañadas de sufrimientos corporales para el reo, como, por ejemplo, la obligación de llevar cadena al pie pendiente de la cintura. En general, puede decirse que la evolución se detiene aquí, por cuanto las directrices fundamentales de esta pena, tal y

${ }^{5}$ CUELLO CALON, E.: Obra citada, pág. 364. 
como habían sido fijadas a lo largo del siglo XIX, van a repetirse, en lo esencial, en el Código de 1928, y con algunas modificaciones, pasará, al de 1932, y de éste, al de 1944.

\section{EL PRESIDIO COMO VERTIENTE PENITENCIARIA}

El presidio se constituye como una plaza fuerte contra el enemigo: es una localización castrense, muchas veces en las fronteras. Estas localizaciones necesitan hombres para su defensa y fortificación y para ello se necesitan penados: unos son desterrados al servicio de armas y otros son desterrados o presidiarios al trabajo de obras. El uso del presidio, como nos dice Figueroa Navarro «no es en nuestro penitenciarismo propiamente castigo, sino necesidad $»^{6}$. Por lo tanto, los penados allí destinados eran utilizados en beneficio del Estado. Rafael Salillas, en su obra Evolución Penitenciaria en España, nos describe las notas que caracterizan esta modalidad de privación de libertad: "creadora de un servicio más bien que de una pena, con la localización de la pena de destierro en un presidio militar, atendió, sobre todo, al cumplimiento del servicio; y si en la galera, en sus limitaciones, en la sujeción al banco y al remo, actuó el imperativo conservador, sin semejantes trabas, en la mayor actividad y desenvoltura de las plazas de guerra, con la variedad de obras en fortificación, en maestranzas y en edificaciones, la tendencia motivadora e invencible suprimió los impedimentos para mayor incremento del trabajo, y la vida penal, en muchos aspectos y manifestaciones, se identificó con la vida libre» ${ }^{7}$. Los presidios militares africanos se convirtieron en ejemplo para los presidios peninsulares que se organizaron en toda la península durante el siglo XIX. Este diseño se convirtió en la primera experiencia de prisión punitiva en España hasta comienzos del siglo XIX.

A partir de aquí quedo constituida la llamada red penitenciaria nacional, dividida en:

A) Establecimientos militares:

1. Presidios africanos (Ceuta, Melilla, Chafarinas, Alhucemas y Peñón de la Gomera).

${ }^{6}$ FIGUEROA NAVARRO, M. C.: Los orígenes del penitenciarismo español. Ed. Edisofer, Madrid 2000, pág. 19.

${ }^{7}$ SALILLAS, R.: Evolución penitenciaria en España. Ed. Analecta, Madrid, 1999, págs. 16-17. 
LA CÁRCEL: INVENCIÓN RECIENTE. SURGIMIENTO DE LA PENA...

2. Presidios peninsulares (Barcelona, Valencia, Málaga, Sevilla, Cádiz y Madrid).

3. Presidios arsenales (Cartagena, El Ferrol y La Carraca).

B) Las cárceles civiles.

Esta pena de presidio se aplicó poco hasta bien entrado el siglo XVIII, ya que las más utilizadas en esa etapa eran las eliminatorias, las corporales y la pena de galeras. El presidio era una pena de prisión destinada para perfiles delincuenciales muy característicos: era un modo de privación de libertad asociado a otros cometidos.

En los presidios africanos, el servicio de armas en las campañas militares que mantenían posiciones en las plazas norteafricanas necesitaba de estos contingentes de penados, pero esa penalidad o destino se podía evitar mediante algún desembolso privado. Estos presidios africanos, según afirma Roldán Barbero constituyeron «una experiencia insólita en la historia del penitenciarismo europeo» ${ }^{8}$.

A principios del siglo XIX, los establecimientos penitenciarios dependían del Ministerio de la Guerra, menos el de Madrid, tal y como nos indica Federico Castejón: «Todos los presidios, excepto el de Madrid que dependía del presidente del consejo real, estaban sujetos a la jurisdicción de Guerra» ${ }^{9}$. Desde comienzos del mencionado siglo, se inició un proceso por el que se fue desgajando de esa dependencia a las prisiones, pasándola sucesivamente, al Ministerio de Fomento o al de Gobernación, para finalizar en el de Gracia y Justicia. Este dinámico cambio es trascendental. Por lo tanto, la pena militar se constituye en comienzo y la mutación de la competencia militar a la civil se produjo de puntillas y de forma progresiva. Cadalso define perfectamente este cambio al afirmar: "sigue siendo militar el personal y la disciplina, pero con tendencias a hacerse civiles. Así el uno como la otra, y porque con el sistema de coerción y el fin utilitario mantenidos hasta entonces, casi de un modo exclusivo, se trata de armonizar la suavidad en el régimen y la corrección del penado, que más tarde habían de tener el debido desarrollo» ${ }^{10}$.

La primera norma penitenciaria no militar en España es la Ordenanza General de Presidios del Reino, de 14 de abril de 1834, siendo

${ }^{8}$ ROLDÁN BARBERO, H.: Historia de la prisión en España. Publicaciones del Instituto de Criminología de Barcelona, 1988, pág. 25.

${ }^{9}$ CASTEJÓN, F.: La legislación penitenciaria española. Ed. Reus, Madrid, 1914, pág. 13.

${ }^{10}$ CADALSO, F.: Instituciones penitenciarias y similares en España. Ed. José Góngora, Madrid, 1922, págs. 331-332.

(C) UNED. Revista de Derecho UNED, núm. 17, 2015 
su origen el Reglamento de 12 de septiembre de 1807. Los responsables militares seguirán por tiempo al frente de los establecimientos penitenciarios, pero despojándose de lo inservible: flexibilizarán el trato y dejarán de mandar a los reclusos como tropa, con objetivos de reforma a través del trabajo, que no será necesariamente forzado. Mientras en otros países de nuestro entorno lo que predomina es el aislamiento, en España se impone el colectivismo en brigadas, talleres y patios.

La Real Orden de 23 de marzo de 1829 impone que los reos militares juzgados por tribunales militares serán destinados a presidio, el cual lo sufrirán en Ceuta y Tarifa, y cuando los tribunales civiles y otras autoridades impongan esa misma pena la cumplirán en los presidios menores de África o a los otros del Reino, excepto los referidos de Ceuta y Tarifa. La razón de esta diferenciación de competencias era fundamentalmente presupuestaria, pues era necesario determinar si era el Ministerio de Hacienda o el de la Guerra el que se hacía cargo de la manutención de los condenados. La duda fue aclarada por la Real Orden de 15 de marzo de 1830, adjudicando la manutención de los presos no militares juzgados por autoridades militares al Ministerio de Hacienda.

Aunque los presidios, en su régimen interior, estaban sujetos a la disciplina militar, la Ordenanza General de Presidios supuso el primer paso para una regulación de las normas sobre el cumplimiento de penas al margen de la normativa militar. El régimen interior militarizado de la Ordenanza de 1834 se prolongo hasta 1903 con la aprobación del Real Decreto de 18 de mayo instituyendo el régimen tutelar.

\section{RECLUSIÓN EN LAS CASAS DE CORRECCIÓN}

Salillas, en el preámbulo de su obra maestra La vida penal en España, estableció cinco grandes categorías en la que podía dividirse la población penal como base de la organización penitenciaria: «Primera: la de los que pueden ser educados, y a estos pertenecen algunos de los jóvenes delincuentes. Segunda: la de los que pueden ser reintegrados, contándose entre ellos los delincuentes por pasión y los de ocasión. Tercera: la de los que deben ser eliminados, que son los delincuentes natos y los incorregibles, según la escala de reincidencia que se gradúe. La de los delincuentes locos o semilocos, destinados a los manicomios judiciales; y la de los incurables, inválidos y ancianos, 
que ingresarán en la penitenciaría-hospital ${ }^{11}$. En el establecimiento de un sistema penitenciario la clasificación ya se considera un criterio básico, pero el logro progresivo de las normas fue costoso, pues la situación concreta no era clara, y de esta manera nos lo hace saber Salillas: «En las grandes cárceles hay, además de las dependencias de los Tribunales, separaciones por categorías de procesados: políticos, distinguidos y menores, pero en la generalidad se confunden toda clase de presos en los patios y dormitorios comunes. En muchas de las cárceles no existe separación de sexos y otras no tenían departamento de presas ${ }^{12}$.

Por su parte, Cadalso nos dice «Poco se había hecho en la práctica respecto de la selección de reclusos, hasta la implantación del nuevo régimen: en el de reclusas no se había hecho ni se ha hecho nada todavía. No sólo por previsión social, sino también por el apoyo debido a la desgracia y hasta por sentimientos humanos, se debe atender a estas desventuradas y librarlas de la perdición que para ellas constituye la cárcel $»^{13}$.

Por lo tanto, en lo que respecta a las prisiones de mujeres, la historia venía suponiendo un trato distinto a las de los hombres, circunstancia que se dilató durante todo el siglo XIX. Ello motivó la existencia de diferentes establecimientos para alojar a las personas de uno $\mathrm{u}$ otro sexo. Concepción Arenal ya precisaba que todo lo que se decía «respecto al hombre penado nos parece aplicable a la mujer, teniendo por un error en la prisión como fuera de ella, establecer entre el espíritu del hombre y el de la mujer diferencias esenciales» ${ }^{14}$.

La andadura de las Casas de corrección de mujeres o casa-galera, que era la denominación empleada, pasaron a depender del Ministerio de la Gobernación, en virtud del Real Decreto de 1 de abril de 1846, y según dispone el Real Decreto de 9 de junio de 1847, que establece el Reglamento para las casas de corrección de mujeres del Reino. Será a partir de 1832, con el Real Decreto de 9 de noviembre, cuando los centros de mujeres y los de hombres pasan de depender del Ministerio de la Guerra al Ministerio de Gobernación. En 1847 existían en España trece casas de corrección de mujeres. Con anterioridad se había empleado el término de galera de mujeres y así lo man-

${ }^{11}$ SALILLAS, R.: La vida penal en España. Imprenta de la Revista de Legislación, Madrid, 1888, pág. 22.

12 SALILLAS, R.: Obra citada anterior, págs. 342-343.

${ }^{13}$ CADALSO, F.: La actuación del Directorio militar en el ramo de prisiones. Imprenta Escuela Industrial de Jóvenes, Alcalá de Henares, 1924, págs. 133-134.

${ }^{14}$ ARENAL, C.: El visitador del preso. En Obras Completas. Tomo XIII, Madrid, 1946, pág. 168 . 
tiene Cadalso al afirmar «que empleamos aquí la palabra galera en el sentido de establecimiento destinado a la reclusión de mujeres delincuentes, vagabundas y de vida licenciosa. Se dio tal nombre a estos establecimientos por razón de sinonimia con las embarcaciones en que los hombres sentenciados a galeras extinguían sus condenas $»^{15}$. En sus origines, la galera estaba destinada a la reclusión de prostitutas y mujeres de mala vida, denominándose galera a la prisión de mujeres y presidio a la prisión de hombres.

Tomás Aranguren, arquitecto que habilitó la galera de Alcalá-mujeres afirma que «las casas de corrección de mujeres, en lo antiguo, se hallaban situadas en las mismas poblaciones que los Presidios, pero no en los mismos locales, hasta que en 1869, por medida económica, se dispuso la reunión del mayor número de las corrigendas en la casa de Alcalá de Henares, que aunque tomando por base un convento de los muchos que existían en la ciudad, se empezó a reformar en 1866 mediante variaciones introducidas en su distribución y construcción de una nueva galería, con destino a correccional de mujeres, sistema de Auburn» ${ }^{16}$. Alcalá de Henares fue la heredera de las galeras de Madrid, las cuales se ubicaban en la calle Montserrat y en la calle del Barquillo. A partir de este momento, las prisiones de mujeres dependerán ya para siempre del mando de los presidios de hombres, y, por lo tanto, cuantas reformas adopten los establecimientos de reclusos se aplicarán a los de presas con posterioridad: su dependencia, en cuanto al tratamiento, será absoluta y plena, y su régimen legal será mínimamente adaptado a su singularidad.

\section{LA IDEA DE LA CÁRCEL-MODELO}

La política penitenciaria de nuestro país estuvo condicionada durante el siglo XIX y principios del XX por la idea de la cárcel-modelo. En dicha cárcel-modelo se resumen los sistemas filadélfico y auburniano y las obras de Beccaria y Howard. El objetivo era que los presidiarios se dedicaran a todas las obras públicas que se deben ejecutar a costa de los fondos de cada Villa.

Vicente Boix se hace eco del intento de implantar una cárcel-modelo en Madrid y así lo indica, en relación con una serie de traslados desde la prisión de Valencia: «No hace mucho tiempo pensó el Go-

${ }^{15}$ CADALSO, F.: Instituciones penitenciarias y similares en España. Ed. José Góngora, Madrid, 1922, pág. 220.

${ }^{16}$ ARANGUREN, T.: Apuntes sobre la reforma del sistema penitenciario de España. Ed. Tip, Madrid, 1871, págs. 13-17. 
bierno español establecer en Madrid, llevado de ese sistema, tantas veces impugnado de una extrema centralización, un presidio modelo, que sirviera de norma a los demás de la península. Al efecto se creyó que el único medio de organizarlo sin grandes trabajos, con poquísimos ensayos y con resultados más inmediatos, era reunir en un edificio, construido sin plan alguno, los artefactos y los operarios que fueran más útiles en los demás establecimientos correccionales, y a este fin el Comandante del presidio de Valencia recibió, como otros, la orden de remitir bien escoltados, los penados que debieran servir de base al presidio modelo» ${ }^{17}$.

El 25 de agosto de 1847, se publica un Real Decreto estableciendo en Madrid tres cárceles-modelos, y mandando que se observase el reglamento que se acompañaba para el régimen y gobierno de todas las capitales de provincia. Esas tres cárceles estaban destinadas a presos, a sentenciados y a mujeres, aunque en ese mismo mes se había establecido una relación de las diferentes casas de corrección, entre las que se incluía la de Madrid. Por lo tanto, el concepto cárcel-modelo, a partir de ese Real Decreto, toma carta de naturaleza propia, para referirse a un tipo especifico de cárcel, aunque en la práctica no se imponga un modelo uniforme, como pudiera deducirse de tales términos. La clasificación interior de la cárcel modelo se distribuía en tres radios o galerías del edificio para cárcel y las otras dos galerías restantes para penas correccionales. Esta distribución fue criticada por autores como Concepción Arenal y por Armengol. Salillas, antes de dirigir la cárcel-modelo de Madrid precisó: „La cárcel de Madrid, destinada a ser el observatorio penitenciario, a precisar las condiciones en que el nuevo sistema es adaptable a nuestro país, y a acreditar el régimen de separación procurando hacer evidentes sus ventajas, por olvido de los correccionalistas entregados a más apremiantes obligaciones, y por falta de una constante observación que revelara los defectos para corregirlos paulatinamente, como se hace con todo ensayo cuando se procede con formalidad y cautela, no es más que un edificio de arquitectura apropiada, un hospital sin patronos ni médicos. El tratamiento, si así puede llamarse, es esencialmente solitario, y las naturales inclinaciones del preso abandonado al hastío de la celda, propenden a restablecer un disimulado hacinamiento» ${ }^{18}$.

${ }^{17}$ BOIX, V.: Sistema penitenciario del presidio correccional de Valencia. Imprenta del presidio, Valencia, 1850, pág. 68.

${ }_{18}$ SALILLAS, R.: La vida penal en España. Ed. José Góngora, Madrid, 1988, pág. 420

() UNED. Revista de Derecho UNED, núm. 17, 2015 
Las tres cárceles-modelos de Madrid fueron la base reglamentaria para todas las cárceles de las capitales de provincia, debiendo ser su clasificación interior la siguiente:

Primero. Departamento para hombres, que se subdividía en:

1. Sección de acusados por delitos leves.

2. Sección de acusados por delitos graves.

3. Sección de sentenciados por delitos leves.

4. Sección de sentenciados por delitos graves.

5. Sección de incomunicados.

6. Sección de jóvenes que no lleguen a la edad de 15 años.

Segundo. Departamento para mujeres, subdividido en los mismos términos que el de hombres, separadas de las adultas las que no lleguen a la edad de 12 años.

\section{PRODUCCIÓN NORMATIVA PENITENCIARIA EN EL SIGLO XIX}

Uno de los caracteres que conforman el siglo XIX es el nuevo fervor legislativo, unificador de normas y, por consiguiente, también florece a lo largo del ochocientos una producción normativa con individualidad propia, una rama del derecho que ampara la necesidad de regir la vida de los internos por criterios uniformes, con independencia del establecimiento en que se ubicaran, y que constituirá una pieza clave en la reforma penitenciaria, siendo en la mayoría de las ocasiones el motor de los cambios en contraste con la desoladora realidad.

En primer lugar tenemos la Ordenanza de Presidios Navales de 20 de marzo de 1804, siendo promulgada esta Real Ordenanza para el Gobierno de los Presidios de los Arsenales de Marina por Carlos III en Aranjuez, a instancias del General Godoy, con el mérito de implantar de forma anticipada un sistema que cabalga entre el utilitarismo y el correccionalismo. A estos destinos fueron enviados, en principio, solo los penados por condenas limpias. Mantenían una gran dureza, incluyendo grilletes, cadenas, apareados, azotes y palos. El desastre de la batalla de Trafalgar marcó el declive de los presidios arsenales de Marina, que ya eran objeto de numerosas críticas, acordándose su supresión en 1818, subsistiendo sólo el de Cádiz, afecto a la Jurisdicción de Marina. 
En segundo lugar tenemos el Reglamento General de Presidios Peninsulares de 12 de septiembre de 1807: A la vista de la congestión existente en los presidios africanos, la solución recayó en los presidios peninsulares, que ya venían existiendo desde 1740. En 1802 se crea en Cádiz el primer presidio peninsular de corte industrial al objeto de frenar los desórdenes ocasionados por vagos y delincuentes que de continuo llegaban a la ciudad. Tras la experiencia de Cádiz, con la aplicación de sus reglamentos particulares, en especial el Reglamento de 26 de marzo de 1805, no se haría esperar mucho la redacción del reglamento de 1807. La condena a obras públicas constituía el ensayo de generalizar por toda la geografía española los presidios según el exitoso modelo manufacturero de Cádiz.

En el reglamento se incluía la ineludible obligación de trabajar incluso en tareas sin utilidad, también se regulaba la asistencia sanitaria y un régimen disciplinario superior en severidad a la Ordenanza de 1804 con castigos corporales infligidos por presidios remunerados (llamados prebostes). La Ordenanza de 1807 no fue un texto modélico, pero sí operativo y de aplicación en todo el territorio nacional. A pesar de que los destinos a presidios de obras públicas se mantuvieron hasta la mitad del siglo XIX, su existencia fue criticada pues la construcción de canales, carreteras, obras portuarias y rehabilitación de ciudades constituía un doble problema: la humillante exposición que ello suponía para los penados, unido a la problemática de vigilancia y riesgo permanente de fuga. En 1843 se promulgo la RO de 2 de marzo como complemento adicional a la Ordenanza General de Presidios del Reino de 1834, siendo su objeto regular el régimen de los destinados a trabajos en obras públicas. A partir de este momento iría cediendo ante la pujanza del taller presidial. Así nos lo expresa Roldán Barbero: «En lo sucesivo, el campo de visión sólo registraría de vez en vez unas figuras diseminadas, semidesnudas, excrecencias de no sofocados ilegalismos y reductos de un tiempo de plena actividad. Contra estas figuras se habían abierto argumentos psicologizantes, intimistas y de ocultación, que las iría diluyendo en nuevas técnicas de utilización de un tiempo sin libertad ${ }^{19}$.

La Real Ordenanza General de los Presidios del Reino de 14 de abril de 1834 representa uno de los más serios y ambiciosos intentos de poner fin al caos legislativo en materia penitenciaria y uno de los primeros deseos de poner los presidios en manos civiles. Tenía 374 artículos divididos en cuatro partes, confirmando la dependencia del

${ }^{19}$ ROLDÁN BARBERO, H.: Historia de la prisión en España. Publicaciones del Instituto de Criminología de Barcelona, 1988, pág. 70. 
Ministerio de Fomento, que tenía su origen en el Real Decreto de 9 de noviembre de 1832. A pesar de la vinculación al poder civil, en su segunda parte, al hablar del régimen interior de los presidios, éste se regula aún impregnado de la vida militar, siendo el cargo de comandante del presidio un jefe militar. La asistencia espiritual y sanitaria recaía en miembros retirados del Ejército o la Armada. En lo referido a la parte disciplinaria, esta se caracterizaba por su especial dureza en los castigos empleándose los palos, los hierros, el encierro, la privación, la reducción o retardo de alimentos, la mordaza y la argolla en patio. Únicamente apreciamos un avance en las garantías hasta el momento inexistentes, traducido en la potestad limitada del comandante, quien sólo podía imponer castigos por faltas leves, siendo la Junta Económica la única que podía sancionar por faltas graves tras un procedimiento sancionador.

La labor legislativa de la Real Ordenanza de 1834 fue completada por la RO de 2 de marzo de 1843, parte adicional reguladora de los destinos a obras públicas, y el Reglamento de 5 de septiembre de 1844, que en realidad está compuesto por ocho reglamentos, y que según Vicente Boix «consignaba todos los principios del sistema del presidio de Valencia ${ }^{20}$. Tras la promulgación de la Real Ordenanza General se van sucediendo diversos Reglamentos particulares, Decretos, RO, circulares..., que van configurando y dando soluciones prácticas en su aplicación. Entre esta profusión legislativa destacan el RD de 23 de junio de 1881 de formación del Cuerpo de funcionarios de prisiones y el RD de 23 de diciembre de 1889 que configura un estatuto especial para Ceuta.

A partir de 1936 se sucedieron numerosas disposiciones tendentes a evitar las corruptelas en el cumplimiento de las penas (sobre todo en la falta de cumplimiento de las formalidades previstas para la tramitación de rebajas de condena). Dichas corruptelas disminuyeron en la década de 1840-50 en base a la supresión de las dispensas de gracias.

A la vez que existían establecimientos de cumplimiento, también convivían con ellos los establecimientos carcelarios y hospicios. Los llamados establecimientos carcelarios estaban destinados a mera custodia y al cumplimiento de penas cortas, y su normativa se basaba en las Ordenanzas de las Audiencias sobre las visitas de Cárceles y obligaciones de los Alcaides de 20 de diciembre de 1835 y el Reglamento para las Cárceles de las capitales de provincia de 25 de agosto

${ }^{20}$ BOIX, V.: Sistema penitenciario del presidio correccional de Valencia, bajo el mando del Coronel Montesinos. Imprenta del presidio, 1850, pág. 109. 
de 1847. En dicha regulación destaca la consignación de la doble dimensión judicial y administrativa de la institución penitenciaria. Esta reseña es importante porque tuvo especial influencia en la gestación de la Ley de Prisiones de 1849, tal y como nos señala Zapatero Sagrado «la normativa de arsenales y presidios fue obra de profesionales del mundo penitenciario, aunque casi todos ellos procedentes del ambiente militar o paramilitar, mientras que la de las cárceles lo fue de hombres del foro. Esto explica los diferentes enfoques de sus preceptos: aquéllos, preocupados principalmente por su gobierno interior, éstos, por la observancia de las garantías procesales de sus forzosos ocupantes» ${ }^{21}$.

La primera etapa del siglo XIX se cierra con la Ley de Prisiones de 26 de julio de 1849. Esta Ley unifica la normativa de presidios y cárceles y marca la división entre cárceles civiles, dependientes del Ministerio de la Gobernación y cárceles militares, dependientes del Ministerio de la Guerra. A partir de este momento se abandona la terminología militar de presidios pasando a la terminología civil de prisiones. Las Juntas Económicas son sustituidas por Juntas de Cárceles en las que se incluye la intervención judicial para velar por el cumplimiento de leyes y reglamentos.

La ley de 1849 clasifica a las prisiones en a) cárceles de Partido y de Capitales de Provincia, para presos preventivos y cumplimiento de arresto mayor, y b) establecimientos penales para cumplimiento de condenas superiores: por un lado, los presidios peninsulares e insulares para cumplimiento de reclusión perpetua o temporal; presidios mayor, menor o correccional; prisión mayor, menor o correccional. Por otra parte los presidios de Ceuta y menores para cumplimiento de cadena perpetua, y finalmente los Arsenales y Destacamentos de Obras Públicas y de Fortificación para cumplimiento de cadena temporal. Esta Ley marcó un camino dejando abiertas las puertas para futuras soluciones reglamentarias, pero su acción, a juicio de Zapatero Sagrado «quedo corta, al dejar sin tratar graves problemas como el de la seguridad de las prisiones, el trabajo de los reclusos y su instrucción, la asistencia sanitaria, el equipo y vestuario, el sistema de pluses y socorros, la problemática de los edificios y la situación administrativa del personal al servicio de las Prisiones ${ }^{22}$.

Es en la segunda mitad del siglo XIX cuando se empieza a ver la verdadera y revolucionaria transformación penitenciaria, del utilita-

${ }^{21}$ ZAPATERO SAGRADO: Los presidios, las cárceles y las prisiones. En ADPCP, Madrid, 1986, págs. 531-532.

22 ZAPATERO SAGRADO. Obra citada, págs. 567-568. 
rismo penal al correccionalismo, con su máximo exponente, el sistema progresivo. Por el contrario, se aprecia cierto receso en la producción de normas generales con vocación unificadora, que dieran nuevos impulsos a los modernos conceptos en el cumplimiento de las penas. La red de hospicios del reino, pasa de ser objeto de la caridad privada a ser amparada por los poderes públicos. Un hecho clave en esta transición fue el Motín de Esquilache, tras el cual se creó la casa de corrección de San Fernando del Jarama, la cual fue elogiada por Howard en su viaje a España. En esta segunda mitad de siglo se engrandece la labor de tutela y corrección, desterrando la ociosidad de la vida interior de los presidios, existiendo excelentes ejemplos como los presidios de Cádiz, Barcelona y Valencia. La segunda mitad del ochocientos se debatía entre el derrumbamiento de la pauta diseñada en la primera mitad del ochocientos, es decir, organización industrial en un marco conventual regido por militares, y las nuevas tendencias intelectuales, que hacían de la filosofía correccional una aspiración incompatible con la militarización de la vida penitenciaria y la utilización de una arquitectura conventual proveniente de la desamortización. Junto a las experiencias en el terreno práctico observamos influencias en Concepción Arenal, Luis Silvela, Salillas, Dorado Montero, Bernaldo de Quirós y en los traductores Giner de los Ríos y Romero Girón. Estas influencias provenían de las obras de Beccaria y Bentham, de la filosofía Krausista y Röderiana y del Marqués de la Rochefoucauld-Liancourt. Hemos de destacar que fueron más los avances intelectuales que los avances prácticos, toda vez la existencia de una gran problemática basada en la arquitectura penitenciaria (las nuevas y escasas construcciones de últimos del siglo XIX fueron de modelo radial) y la negativa de los militares a perder el dominio de las prisiones (hasta la primera república no se consiguió crear a través del RD de 23 de junio de 1881 el Cuerpo de Funcionarios de Prisiones). Hasta la entrada del siglo XX no vemos nuevos decretos para procurar avances legislativos: los más importantes fueron el Real Decreto de 3 de junio de 1901 (de influencia cadalsiana), el Real Decreto de 18 de mayo de 1903 (de inspiración salillista) y el Real Decreto de 5 de mayo de 1913 (para dar unidad, armonía, agrupar y clarificar el sinnúmero de preceptos).

La verdadera y total implantación del ansiado sistema progresivo no se logra hasta la promulgación del Decreto de 23 de julio de 1914, en el que se establece la libertad condicional y la entrada en funcionamiento del Reformatorio de Ocaña en la provincia de Toledo. 


\section{CONCLUSIÓN PERSONAL}

En un período de transición como el que transcurre entre las tres últimas décadas del siglo XVIII y la primera del siglo XIX coexistieron varios sistemas punitivos: la pena de muerte, el trabajo forzado público (tanto militar como civil), el encierro penitenciario de carácter custodial junto a la privación punitiva de libertad en los presidios, y las ideas utilitaristas de la pena cada vez más teñidas del incipiente correccionalismo proveniente de otras latitudes. Por otra parte, la ausencia de un sistema de clasificación de reclusos seguía provocando, junto a situaciones de hacinamiento, otras que revelaban la persistencia entre presos preventivos junto a algunos penados $\mathrm{y}$, asimismo, sin ningún tipo de selección en función de sus presuntas responsabilidades penales. Además, la existencia de corrupción generalizada, del tormento judicial o procesal (destinado a lograr la confesión del acusado), la lentitud de los procesos y al prolongada duración de la prisión preventiva, dibujan un panorama que referido a los derechos más elementales de los reclusos, se traduce en unas pésimas condiciones de vida para estos. Ello se agrava más con la denominada indeterminación de las penas y la llamada cláusula de retención (que fundamentalmente se aplicaba a las penas de presidios, arsenales o minas): ello significaba que, aunque aparentemente la condena era por tiempo definido, cuando el condenado extinguía la pena impuesta podía quedar retenido en el establecimiento sin poder salir sin permiso del Rey o del tribunal sentenciador. Todo ello unido al aumento del poder discrecional de las autoridades penitenciarias, conforman un marco de profunda degradación de los derechos de las personas privadas punitivamente de su libertad. Habrá que esperar todavía algún tiempo para que pueda verificarse algún avance en el proceso de reconocimiento de tales derechos fundamentales.

\section{BIBLIOGRAFÍA}

ARANGUREN, T.: Apuntes sobre la reforma del sistema penitenciario de España, Madrid, 1871.

ARENAL, C.: El visitador del preso. En Obras Completas. Tomo XIII. Madrid, 1946

BOIX, V.: Sistema penitenciario del presidio Correccional de Valencia, bajo el mando del Coronel Montesinos, Valencia, 1850.

CADALSO, F.: Estudios penitenciarios. Presidios españoles, escuela clásica y positiva y colonias penales, Madrid, 1895.

(C) UNED. Revista de Derecho UNED, núm. 17, 2015 


\section{José GinÉs CARRAsco GuIJARRo}

CADALSO, F.: Instituciones penitenciarias y similares en España, Madrid, 1922.

CADALSO, F.: La actuación del Directorio militar en el ramo de prisiones, Alcalá de Henares, 1924.

CADALSO, F.: La pena de deportación y la colonización por penados, Madrid, 1985.

CADALSO, F.: Principios de colonización y colonias penales, Madrid, 1986.

CASTEJON, F.: La Legislación penitenciaria española, Madrid, 1914.

CASTEJON, F.: Criminalidad y represión en el antiguo y en el nuevo régimen, Madrid, 1932.

CUELLO CALON, E.: La moderna penología, Barcelona, 1958. 